\title{
Reasons for use, potential use, or discontinued use of hookah among US young adult college students
}

\author{
Shreya Kothari', Carla J. Berg ${ }^{1,2,3}$
}

\begin{abstract}
INTRODUCTION Given the increase in hookah use among young adults, characteristics of hookah use/users, as well as reasons for its use or discontinuation among young adults, are critical to understand.

METHODS Data from a study of 18-25 year olds from seven Georgia colleges/universities $(n=2865)$ were analyzed to examined: 1$)$ differences in socio-demographics and other substance use among current (past 4 months), never, and former hookah users; 2) use characteristics among current users (e.g. device types/flavors used, quit intentions); and 3) reasons for use, potential use, and discontinued use among current, never, and former users.

RESULTS Of the students, $56.3 \%$ were never users, $12.4 \%$ were current, and $31.3 \%$ former users. Correlates of being a current (vs never) user included being 'other race' (vs White), attending a historically black college/university (HBCU vs technical college), and use of other substances. Correlates of being a former (vs never) hookah user included being older (vs younger), being 'other race' (vs White), attending an HBCU (vs technical college), and use of other tobacco products, marijuana, or alcohol. Among current users, $73.7 \%$ reported no intention to quit; $26.2 \%$ attempted to quit in the past year. Two factors were identified regarding reasons for current use (flavors, social reasons): one factor regarding potential use among never users (related to flavors and social factors), and three factors regarding discontinued use (inconvenience, anti-tobacco attitude, social reasons).

CONCLUSIONS Findings indicate the risk factors for hookah use and the importance of particular factors (e.g. flavors, social influences) relevant to regulation/policy.
\end{abstract}

AFFILIATION

1 Hubert Department of Global Health, Rollins School of Public Health, Emory University,

Atlanta, United States 2 Department of Behavioral Sciences and Health Education, Rollins School of Public Health, Emory University, Atlanta, United States

3 Winship Cancer Institute, Emory University, Atlanta, United States

\section{CORRESPONDENCE TO}

Carla J. Berg. Department of Behavioral Sciences and Health Education, Rollins School of Public Health, Emory University, 1518 Clifton Road NE, GA 30322 Atlanta, United States. Email: cjberg@emory.edu

\section{KEYWORDS}

substance use, tobacco use, substance use, young adults, risk factors

Received: 15 August 2017 Revised: 13 December 2017 Accepted: 5 January 2018

\section{INTRODUCTION}

Tobacco use is the single most preventable cause of death in the United States ${ }^{1}$, causing 438000 premature deaths annually ${ }^{2}$. Although the prevalence of cigarette smoking is decreasing, use of alternate tobacco products have increased ${ }^{3}$. The use of one such tobacco product, hookah or waterpipe, has become a global epidemic among young people ${ }^{4}$. As a result of its growing popularity, hookah use has become a threat to public health.

In terms of health consequences, hookah users absorb nicotine in amounts comparable to cigarette smokers and absorb more carbon monoxide ${ }^{5}$. Both hookah and cigarettes have substances like nicotine, tar, carbon monoxide, and deleterious gases such as volatile aldehydes, ultrafine particles, and polycyclic aromatic hydrocarbons6. Hookah users are also exposed to charcoal combustion ${ }^{6,7}$, and the spread of infections from sharing the same mouthpiece and hose $^{8}$. Additionally, hookah users may experience nicotine-dependence symptoms earlier than cigarette smokers9. Despite these risks, young people are generally unaware of the constituents of hook $\mathrm{h}^{10}$, and believe that hookah use is less harmful, less polluting, 
and less addictive than cigarette smoking ${ }^{11,12}$.

In addition to misperceptions of the low harms of hookah use, social image and facilitation may be reasons for hookah use. Among young adults, hookah use appears trendy and cool ${ }^{13,14}$, and is socially acceptable among friends and peers ${ }^{15,16}$. Peer hookah use influences use of hookah ${ }^{12,17}$. People prefer consuming hookah over alcohol ${ }^{16}$, as it is more affordable and its cost can be shared among friends ${ }^{18}$. Emergence of hookah bars and cafes near college/ university campuses intensifies concerns about the vulnerability of students initiating hookah ${ }^{19}$. In addition, restaurants have increasingly begun to offer hookah in response to the demand by the consumers and competitors ${ }^{19}$, which may influence people to experiment with $\mathrm{it}^{20}$.

The tobacco marketplace has also diversified in terms of hookah design (e.g. personal devices) ${ }^{21}$ and flavors ${ }^{22,23}$. Creative ideas have been devised for fluid storage bowls, such as cored pineapples or watermelon, and carving an orange or an apple; or using shiny ornaments and crystal bottles to appeal to women in particular ${ }^{21,24}$. Flavored tobacco, along with attractive and seemingly healthy packaging, has attracted youth ${ }^{25,26}$. The smell and taste of flavored tobacco is more enticing, and overall the experience has been reported to be more pleasant when compared to cigarette smoking ${ }^{27,21}$. Additionally, the ability to personalize hookah, including mixing flavors and performing smoking tricks, allures youth ${ }^{13,24}$.

Media have a strong influence in successful marketing and promoting hookah use among young adults $^{28,29}$. Prominent marketing strategies include advertisements on televisions ${ }^{30}$, and showing waterpipe tobacco smoking in movies ${ }^{21}$, as well as satisfying the online demand for information and driving social media activity surrounding hookah ${ }^{28,31}$. Indeed, the waterpipe industry leverages various media channels to promote, market, and sell their product to the public, marketing hookah as a safer alternative to conventional tobacco products ${ }^{31,32}$.

Considering the rise of hookah use in young adults, it is paramount to understand the individual and socio-contextual characteristics associated with the reasons for its use. Bandura's Social Cognitive Theory (SCT) ${ }^{33}$ indicates the importance of outcome expectancies and social influence on health behaviors, including hookah $\mathrm{use}^{33}$. The aforementioned research highlights the influences of perceptions of harm, social factors, and the draw of product design and marketing. However, there is limited previous research that aimed to quantitatively examine who is most likely to initiate or sustain hookah use, the characteristics of hookah use among users, or the range of potential reasons (e.g. outcome expectancies) for use, potential use, or discontinued use of hookah.

Given the aforementioned literature and the gaps in the research, the aims of this study were to: 1) assess differences in socio-demographics and other substance use among current (past 4 months), never, and former users of hookah; 2) characterize hookah use among current users (e.g. use levels, places of use, types of devices used, flavors most frequently used, quit intentions and confidence); and 3) assess reasons for use, potential use, and discontinued use among current, never, and former hookah users, in the young adult population.

\section{METHODS}

\section{Study design}

The current study is an analysis of data from Project DECOY: Documenting Experiences with Cigarettes

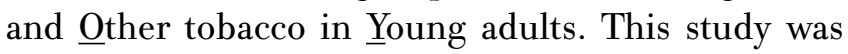
approved by Emory University and ICF International Institutional Review Boards, as well as those of the participating colleges. The methods employed in Project DECOY are documented in detail elsewhere ${ }^{34}$. In short, the parent study involved a 2-year longitudinal cohort study involving 3418 racially/ ethnically diverse young adults attending seven Georgia colleges/universities. Data collection began in Fall 2014 and consisted of individual assessments every 4 months for 2 years (Fall, Spring, Summer).

\section{Participants}

The primary sampling frame includes seven Georgia campuses, including two public universities, two private colleges/universities, two community/ technical colleges, and a historically black university with representation from rural and urban settings. The rationale for sampling from these institutions was to obtain a broad range of young adults in terms of socio-demographic backgrounds and to put study findings in the context of campus-related factors and campus tobacco control policies/activities. Inclusion 
criteria for participants were: 1 ) age $\geq 18$ and $\leq 25$ (to include the broad range of young adult ages, but reduce overall age variability), and 2) ability to read English.

College email addresses were obtained from the Registrar's office from each college/university for students meeting eligibility criteria. Three thousand 18-25 year-old adults were randomly selected from one private and two public universities. The remainder of the schools had 18-25 year-old student populations of fewer than 3000; thus, the entire student population of that age range at those schools was included in recruitment. Our total response rate of $22.9 \%$ ( $\mathrm{N}=3574 / 15607)$, albeit low, was over a very short period and met our sampling targets. We employed a graduated compensation schedule (\$30 for the first two assessments, $\$ 40$ for the second two, $\$ 50$ for the final two), with an additional $\$ 100$ incentive for participating in all assessments. The current analyses examined data from the Wave 3 assessment of the study, which was conducted during July/August 2015. The sample size during Wave 3 was 2865 (83.8\% retention rate).

\section{Measures}

The current analyses focused on factors related to hookah use (e.g. places used, types/flavors used, reasons for use, potential use, discontinued use), other tobacco and substance use behaviors, and socio-demographics.

Hookah use. The hookah users have been characterized into never users, current users (using hookah at least 1 day within the past 4 months) and former users (had used in their lifetime, but not within the past 4 months). A 4-month period was used because our assessments occurred every 4 months; thus, this assessment provided a complete characterization of hookah use over the 2-year study period. (We also assessed within the past 30 days hookah use but chose to use the 4-month period, given the infrequency of hookah use reported by participants and the desire to assess reasons for use among even infrequent users.) We created new items to assess places of hookah use, types of hookah devices used, and flavors most frequently used. To assess places of use, we asked, 'In the past 4 months, where have you used hookah?', with response options of: 'at a hookah bar or other public establishment, at someone else's home, at your home, or other'. Types of hookah devices used was assessed by asking, "Which of the following types of hookah pipes have you used in the past 4 months?', with response options of: 'a larger hookah pipe that sits on the table, a personal handheld hookah device that can be easily carried with you, or other'. To assess flavors most frequently used, we asked, 'What flavors of tobacco (shisha) from a hookah or water pipe do you use most of the time? Check up to 3'. The response options were: 'tobacco; menthol or mint; fruit flavors; coffee or tea; alcoholic drink flavors (for example mojitos and daquiris); caramel, vanilla, chocolate, and cream; candy flavors (for example licorice, gummy bears, or bubble gum); other food flavors (for examples cupcakes or muffin); or other'.

Hookah quitting-related factors. We adapted items used for cigarettes to examine confidence in quitting hookah use, importance of quitting, readiness to quit, and previous quit attempts. We asked participants, 'On a scale of 1 being not at all confident and 10 being extremely confident, how confident are you that you could quit using hookah if you wanted to?' and 'On a scale of 1 being not at all important and 10 being extremely important, how important is it to you that you quit using hookah?' ${ }^{35}$. To assess readiness to quit, we asked, "Are you seriously thinking about quitting the use of hookah?', with response options of: Yes, within the next 30 days; Yes, within the next 6 months; Yes, in more than 6 months; I am not thinking about quitting the use of hookah. We dichotomized this variable as intending to quit in the next 30 days versus not. To assess quit attempts, we asked, 'During the past 12 months, how many times did you stop using hookah for one day or longer because you were trying to quit using hookah for good?', with a dropdown box from 0 to 31 or more times. This variable was dichotomized as: made at least one quit attempt in the past 12 months versus no attempt.

Reasons for hookah use and discontinued use. Items regarding reasons for hookah use, potential use, and discontinued use were based on qualitative interviews conducted at Wave 2 and developed and refined by our research team (manuscripts currently under review). Participants reporting a within past-4months use of hookah were instructed, 'You indicated that you have used hookah at least once in the past 4 
months. Below are some reasons for why you might use hookah'. Items are listed in Table 1. Participants reporting no use of hookah in their lifetime were instructed, 'You indicated that you have never used hookah. Below are some reasons for why you might use hookah'. Items are listed in Table 2. Participants reporting lifetime, but not within past-4-months use of hookah were instructed, 'You indicated that you have used hookah at least once in your lifetime but have not used hookah in the past 4 months. Below are some reasons for why you might have quit using hookah'. Items are listed in Table 3. All participants were instructed, 'Please indicate how true each of these reasons are for you using the scale below'
Table 1. Reasons for use of hookah among current (past 4 months) hookah users

\begin{tabular}{|c|c|c|c|}
\hline & Instrumentality & Social & M (SD) \\
\hline Hookah doesn't smell badly & 0.83 & 0.45 & $2.59(1.81)$ \\
\hline Hookah comes in appealing flavors & 0.91 & 0.48 & $3.39(1.91)$ \\
\hline $\begin{array}{l}\text { I like experimenting with the various } \\
\text { flavors }\end{array}$ & 0.90 & 0.53 & $2.93(1.97)$ \\
\hline $\begin{array}{l}\text { I like the buzz I get from nicotine } \\
\text { but do not like regular cigarettes }\end{array}$ & 0.70 & 0.57 & $2.15(1.73)$ \\
\hline Hookah helps me relax & 0.78 & 0.65 & $2.53(1.81)$ \\
\hline $\begin{array}{l}\text { People who are important to me use } \\
\text { hookah }\end{array}$ & 0.52 & 0.78 & $2.06(1.57)$ \\
\hline $\begin{array}{l}\text { I use hookah because I think they } \\
\text { are cool or intriguing }\end{array}$ & 0.57 & 0.81 & $2.16(1.59)$ \\
\hline $\begin{array}{l}\text { I like socializing with other hookah } \\
\text { users }\end{array}$ & 0.58 & 0.72 & $2.82(1.81)$ \\
\hline I like the image of me it reflects & 0.37 & 0.86 & $1.61(1.30)$ \\
\hline Cronbach's alpha & 0.89 & 0.81 & \\
\hline
\end{tabular}

Note: On a scale of 1-not at all true for me to 6-extremely true for me.

Extraction Method: Principal Component Analysis. Rotation Method: Promax with Kaiser Normalization.
Table 2. Reasons for potential use of hookah among never users of hookah

$\begin{array}{lcc} & \text { Factor } & \text { VI (SD) } \\ \begin{array}{l}\text { Hookah doesn't smell } \\ \text { badly }\end{array} & 0.73 & 1.19(0.70) \\ \begin{array}{l}\text { Hookah comes in } \\ \text { appealing flavors }\end{array} & 0.82 & 1.37(1.00) \\ \begin{array}{l}\text { I like the buzz I get } \\ \text { from nicotine but } \\ \text { do not like regular } \\ \text { cigarettes }\end{array} & 0.73 & 1.11(0.55) \\ \begin{array}{l}\text { I would like socializing } \\ \text { with other hookah } \\ \text { users }\end{array} & 0.82 & 1.29(0.88) \\ \begin{array}{l}\text { People in the media or } \\ \text { other public figures use } \\ \text { hookah }\end{array} & 0.65 & 1.32(0.98) \\ \begin{array}{l}\text { Cronbach's alpha } \\ \text { rothe }\end{array} & 0.80 & \end{array}$

Note: On a scale of 1-not at all true for me to 6-extremely true for me. Extraction Method: Principal Component Analysis. One component extracted.

Table 3. Reasons for discontinued use of hookah among former users of hookah

\begin{tabular}{|c|c|c|c|c|}
\hline & Inconvenience & Anti- tobaceo & Social & M (SD) \\
\hline I didn't like the buzz & 0.85 & 0.55 & 0.42 & $2.57(2.01)$ \\
\hline I didn't like the flavor & 0.91 & 0.48 & 0.46 & $2.29(1.90)$ \\
\hline It was messy & 0.86 & 0.42 & 0.53 & $2.26(1.86)$ \\
\hline It was too expensive & 0.78 & 0.44 & 0.54 & $2.55(1.92)$ \\
\hline I didn't like the smell & 0.89 & 0.50 & 0.56 & $2.28(1.86)$ \\
\hline I just don't think about it & 0.39 & 0.62 & 0.31 & $3.84(2.15)$ \\
\hline I quit tobacco/nicotine all together & 0.42 & 0.83 & 0.51 & $3.11(2.30)$ \\
\hline I don't like idea of using any kind of nicotine/tobacco & 0.49 & 0.89 & 0.56 & $3.46(2.30)$ \\
\hline I think it's unhealthy & 0.50 & 0.86 & 0.56 & $3.64(2.20)$ \\
\hline My friends don't use tobacco & 0.45 & 0.65 & 0.76 & $2.66(2.03)$ \\
\hline Someone important to me asked me not to use it & 0.41 & 0.33 & 0.77 & $2.04(1.81)$ \\
\hline It hasn't come up in social situations & 0.30 & 0.52 & 0.69 & $3.06(2.13)$ \\
\hline I think it is weird or socially unacceptable & 0.64 & 0.47 & 0.84 & $2.04(1.71)$ \\
\hline I didn't like the image it projected about me & 0.60 & 0.60 & 0.78 & $2.61(2.07)$ \\
\hline Cronbach's alpha & 0.91 & 0.83 & 0.83 & \\
\hline
\end{tabular}

Note: On a scale of 1-not at all true for me to 6-extremely true for me.

Extraction Method: Principal Component Analysis. Rotation Method: Promax with Kaiser Normalization. 
(response options of 1-not at all true to 6-extremely true).

Other tobacco and substance use. Participants were first asked to report the number of days they used each product within the past 4 months (to cover the duration of time between each wave of assessment): cigarettes, little cigars or cigarillos (LCCs), smokeless tobacco, e-cigarettes, alcohol, and marijuana ${ }^{1}$. Those who reported any use within the past 4 months were then asked to report the number of days they used the respective product in the past 30 days. Given the distributions of use, alcohol use was used as a continuous variable, while tobacco and marijuana use were dichotomized as: current (past 30 days) users vs non-users.

Socio-demographics. We assessed age, sex, race/ ethnicity, and type of school attended (e.g. private college/university, public university, historically black college/university [HBCU], technical college).

\section{Data analyses}

First, we characterized our sample using descriptive statistics. We then conducted bivariate analyses to examine differences in socio-demographics and other substance use among never, current, and former hookah users. We then compared current and former users to never users (reference group) using multinomial logistic regression. Next, for each of the subpopulations (current, never, former hookah users), we conducted an exploratory factor analysis on the respective sets of items assessing reasons for use among current users, potential reasons for use among never users, and reasons for discontinued use among former users, respectively, using Promax rotation. We used eigenvalues of greater than 1 as the criterion for number of factors. We then conducted bivariate analyses examining subscale scores in relation to correlates of interest (socio-demographics, among current users, quit intentions and attempts). Analyses were conducted in SPSS 23.0, and alpha was set at 0.05 .

\section{RESULTS}

\section{Participant characteristics}

Among the 2865 participants in the study, the average age was $20.53(\mathrm{SD}=1.93), 64.4 \%(\mathrm{n}=1846)$ were female, 1823 (63.6\%) were White, 645 (22.5\%) Black, 192 (6.7\%) Asian, 205 (7.2\%) Other, and 218
(7.6\%) Hispanic. In our sample, never users were $56.3 \%$, current (past 4 months) users $12.4 \%$, and former users (those who had used in their lifetime but not in the past 4 months) $31.3 \%$.

\section{Correlates of never, current, and former hookah users}

Differences in hookah-use status were found between the never, current, and former users in age $(p<0.001)$, sex $(p=0.034)$, race/ethnicity $(p<0.001)$, type of school attended $(\mathrm{p}<0.001)$, and use of each tobacco product, marijuana, and alcohol use (all with $\mathrm{p}<0.001$, Table 4 ). In the multinomial logistic regression examining differences between never, current, and former users (not shown in Tables), correlates of being a current (vs never) hookah user included being 'other race' (vs White, $\mathrm{p}=0.004$ ), attending an HBCU (vs a technical college, $\mathrm{p}<0.001$ ), and use of any other tobacco product, marijuana, or alcohol (all with $\mathrm{p}<0.001$ ). Correlates of being a former (vs never) hookah user included being older $(p<0.001)$, being 'other race' (vs White, $p=0.009$ ), attending an HBCU (vs a technical college, $\mathrm{p}=0.01$ ), and use of any other tobacco product (except LCGs), marijuana, or alcohol (all with $\mathrm{p}<0.001$, Nagelkerke R-squared=0.289).

\section{Characteristics of hookah use among past-4- months users}

Of the 354 past-4-months hookah users, average number of days of use was 4.53 ( $\mathrm{SD}=12.43)$. Whereas, of the 226 past-30-days hookah users, the average number of days of use was $3.04(\mathrm{SD}=4.46)$. Among past-4-months users, 186 (52.5\%) reported using hookah most frequently at a bar, followed by $116(32.8 \%)$ who used it at someone else's home, and $48(13.6 \%)$ who used it at their own home. Of the past-4-months hookah users, $316(89.3 \%)$ used large hookah, whereas 35 (9.9\%) participants used the handheld type. When asked to select three most commonly used hookah flavors, $310(87.6 \%)$ chose fruit flavors, $107(30.2 \%)$ selected menthol or mint flavor, and $100(28.2 \%)$ chose candy flavors. On average, confidence in quitting hookah was high $(\mathrm{M}=8.48, \mathrm{SD}=3.25)$; however, average importance of quitting hookah was low $(\mathrm{M}=2.61, \mathrm{SD}=3.41)$. In addition, $261(73.7 \%)$ reported no intention to quit, but $58(16.4 \%)$ reported readiness to quit using hookah in the next 30 days. Finally, 93 (26.2\%) 
Table 4. Participant characteristics and bivariate analyses examining differences between hookah never users, current (past 4 months) users, and former users (lifetime users, but not in past 4 months)

\begin{tabular}{|c|c|c|c|c|c|}
\hline & $\begin{array}{l}\text { Total sample } \\
\text { V (SD) } \\
\left.\text { or N ( }{ }^{\circ} \%\right) \\
\text { N } 2865\end{array}$ & $\begin{array}{l}\text { Vever users } \\
\text { V (SD) } \\
\text { or N }\left({ }^{\circ} \%\right) \\
\text { N } 1611\end{array}$ & $\begin{array}{c}\text { Past I months } \\
\text { users } \\
\text { V (SD) } \\
\text { or N }(\%) \\
\text { N } 351\end{array}$ & $\begin{array}{l}\text { Former users } \\
\begin{array}{l}\text { M (SD) } \\
\text { or N }(\%) \\
\text { V } 897\end{array}\end{array}$ & $p$ \\
\hline \multicolumn{6}{|l|}{ Socio-demographics } \\
\hline Age (SD) & $20.53(1.93)$ & $20.31(1.89)$ & $20.43(1.77)$ & $20.97(2.00)$ & $<0.001$ \\
\hline $\operatorname{Sex}(\%)$ & & & & & 0.034 \\
\hline Female & $1846(64.4)$ & $1073(66.5)$ & $219(61.9)$ & $554(61.8)$ & \\
\hline Male & $1019(35.6)$ & $541(33.5)$ & $135(38.1)$ & $343(38.2)$ & \\
\hline Race (\%) & & & & & $<0.001$ \\
\hline White & $1823(63.6)$ & $1091(67.6)$ & $170(48.0)$ & $562(62.7)$ & \\
\hline Black & $645(22.5)$ & $319(19.8)$ & $121(34.2)$ & 205 (22.9) & \\
\hline Asian & $192(6.7)$ & $107(6.6)$ & $31(8.8)$ & $54(6.0)$ & \\
\hline Other & $205(7.2)$ & $97(6.0)$ & $32(9.0)$ & $76(8.5)$ & \\
\hline Hispanic (\%) & $218(7.6)$ & $111(6.9)$ & $34(9.6)$ & $73(8.1)$ & 0.166 \\
\hline Type of school (\%) & & & & & $<0.001$ \\
\hline Public & $804(28.1)$ & $429(26.6)$ & $120(33.9)$ & $255(28.4)$ & \\
\hline Private & $1224(42.7)$ & $711(44.1)$ & $142(40.1)$ & $371(41.4)$ & \\
\hline Technical college & $516(18.0)$ & $326(20.2)$ & $29(8.2)$ & $161(17.9)$ & \\
\hline $\mathrm{HBCU}$ & $321(11.2)$ & $148(9.2)$ & $63(17.8)$ & $110(12.3)$ & \\
\hline \multicolumn{6}{|c|}{ Current other tobacco use } \\
\hline Cigarettes & $334(11.7)$ & $78(4.8)$ & $90(25.4)$ & $166(18.5)$ & $<0.001$ \\
\hline Smokeless tobacco & $81(2.8)$ & $13(0.8)$ & $27(7.6)$ & $41(4.6)$ & $<0.001$ \\
\hline E-cigarettes & $158(5.5)$ & $35(2.2)$ & $53(15.0)$ & $70(7.8)$ & $<0.001$ \\
\hline LCC & $156(5.4)$ & $33(2.0)$ & 69 (19.4) & $54(6.0)$ & $<0.001$ \\
\hline \multicolumn{6}{|c|}{ Current other substance use } \\
\hline Marijuana & $357(12.5)$ & $74(4.6)$ & $111(31.4)$ & $172(12.5)$ & $<0.001$ \\
\hline Alcohol & $1844(64.4)$ & $865(53.6)$ & $287(81.1)$ & $692(77.1)$ & $<0.001$ \\
\hline Binge drinking & $891(31.1)$ & 295 (18.3) & $179(50.6)$ & $417(46.5)$ & $<0.001$ \\
\hline
\end{tabular}

reported attempting to quit use of hookah in the past 12 months.

\section{Reasons for hookah use among current users}

The reasons for hookah use among current users assessed are listed in Table 1. Two primary factors emerged: 1) instrumentality (e.g. doesn't smell badly, appealing flavors; Cronbach's alpha=0.89), and 2) social reasons (e.g. people important to me use hookah, the image it reflects; Cronbach's alpha=0.81). The reason most highly rated on average was that it comes in appealing flavors $(\mathrm{M}=3.39, \mathrm{SD}=1.91)$, followed by liking to experiment with the flavors $(\mathrm{M}=2.93$, $\mathrm{SD}=1.97)$. The lowest rated reason was liking the image that using hookah reflects $(\mathrm{M}=1.61, \mathrm{SD}=1.30)$.
Bivariate analyses indicated that reasons for use did not differ by age, sex, race/ethnicity, type of school attended, or past-12-months hookah quit attempts. However, greater likelihood of reporting readiness to quit using hookah in the next 30 days was associated with lower scores on both instrumentality $(\mathrm{M}=2.32$, $\mathrm{SD}=1.41$ vs $\mathrm{M}=2.80, \mathrm{SD}=1.55$ for those not ready to quit, $\mathrm{p}=0.030)$ and social reasons $(\mathrm{M}=1.83, \mathrm{SD}=1.13$ vs $\mathrm{M}=2.23, \mathrm{SD}=1.28$ for those not ready to quit, $\mathrm{p}=0.029$ ).

Reasons for potential hookah use among never users The reasons for hookah use among never users assessed are listed in Table 2. Only one primary factor emerged (Cronbach's alpha $=0.80$ ). The reason most highly rated on average was that it comes in 
appealing flavors $(\mathrm{M}=1.37, \mathrm{SD}=1.00)$, followed by liking to socialize with other hookah users $(\mathrm{M}=1.29$, $\mathrm{SD}=0.88$ ). The lowest rated reason was that people in the media or other public figures use hookah $(\mathrm{M}=1.32, \mathrm{SD}=0.62)$.

Bivariate analyses indicated that reasons for potential use did not differ by age, sex, or type of school attended. However, scores for Whites were higher than for Blacks and Asians $(\mathrm{M}=1.93, \mathrm{SD}=0.51$ vs $\mathrm{M}=1.41, \mathrm{SD}=0.84$ for Blacks and $\mathrm{M}=1.43, \mathrm{SD}=0.75$ for Asians, $\mathrm{p}<0.001$ ).

\section{Reasons for discontinued hookah use in former users}

The reasons for discontinued hookah use among former hookah users assessed are listed in Table 3 . Three primary factors emerged: 1 ) inconvenience (e.g. too messy/expensive, didn't like smell, flavor, buzz; Cronbach's alpha=0.91), 2) anti-tobacco attitude (e.g. quit tobacco/nicotine all together, it's unhealthy, Cronbach's alpha=0.83), and 3) social reasons (e.g. didn't like the image it projected, someone asked me not to use; Cronbach's alpha $=0.83$ ). The reason most highly rated, on average, was that they just didn't think about it $(\mathrm{M}=3.84, \mathrm{SD}=2.15)$, followed by thinking it's unhealthy $(\mathrm{M}=3.64, \mathrm{SD}=2.20)$. The lowest rated reasons were that someone asked them not to use it $(\mathrm{M}=2.04, \mathrm{SD}=1.81)$, and thinking it was weird or socially unacceptable $(\mathrm{M}=2.04, \mathrm{SD}=1.71)$.

Bivariate analyses indicated that reasons for discontinued use did not differ by age, race/ ethnicity, or type of school attended. However, females had higher scores in relation to anti-tobacco attitudes or health concerns $(\mathrm{M}=3.72, \mathrm{SD}=1.84$ vs $\mathrm{M}=3.18, \mathrm{SD}=1.73$ for males, $\mathrm{p}<0.001$ ), social reasons $(\mathrm{M}=2.61, \mathrm{SD}=1.55$ vs $\mathrm{M}=2.27, \mathrm{SD}=1.43$ for males, $\mathrm{p}=0.024)$, and inconvenience $(\mathrm{M}=2.48, \mathrm{SD}=1.72 \mathrm{vs}$ $\mathrm{M}=2.24, \mathrm{SD}=1.49$ for males, $\mathrm{p}<0.001)$.

\section{DISCUSSION}

The purpose of this study was to identify correlates of never, current (past 4 months), and former hookah use, and to enhance our understanding of how young adults use hookah, as well as their reasons for use, potential use, or discontinued use. In our sample, $12.4 \%$ were current hookah users, and $31.3 \%$ were former hookah users. This is in agreement with other studies on hookah-use prevalence among young adults ${ }^{1,5,36-38}$.

In terms of correlates of hookah-use status, being older was associated with being a current or former hookah user, as was found in other studies of hookah uses in young adulthood ${ }^{39,40}$. Men were more likely than women to report current or former hookah use, consistent with other research ${ }^{39,41}$. Nevertheless, there is growing concern about hookah use among women, globally ${ }^{42,43}$. Evidence suggests that positive attributes associated with hookah use have promoted its use among women ${ }^{44}$. Current findings also show that there was no difference in its consumption based on sexual orientation. In terms of race/ethnicity, Blacks were more likely to be current or former hookah users compared to other races. Hookah use is common among racial/ethnic groups where it is a cultural pastime, like the Arab populations, but it is on the rise among other racial groups in the United States $^{45}$. Disparities among hookah use warrant further study, with particular attention to culture, race, and ethnicity, to tailor smoking interventions. Nearly $30 \%$ of public school and $20 \%$ of HBCU students were current hookah smokers, and $30 \%$ and $10 \%$ were former users, respectively. Finally, current use of any other tobacco product, marijuana, or alcohol was associated with increased odds of current or former hookah use, which is in line with previous findings ${ }^{29,46}$.

Regarding characteristics of hookah use, most of the participants consumed the larger floor/table top at a bar, most frequently. Findings from this study are consistent with the literature, indicating that people predominantly prefer using hookah in a social setting, as it is a shared communal experience ${ }^{16,22}$, and that hookah cafes and bars are becoming popular places to socialize $\mathrm{e}^{37}$. The majority of respondents used characteristically flavored tobacco products out of which fruit flavor was dominant. Their cartons are often packaged with fruit displays, making them appear as healthy products for hookah consumers ${ }^{47}$, along with advertisements that have made flavored tobacco products popular. On average, current hookah users reported that quitting hookah use was not very important. This could be because some believe using tobacco in a waterpipe is seemingly healthier, less addictive than cigarettes ${ }^{27}$, and believe they could quit at anytime ${ }^{28}$. Moreover, hookah users who are likely not to use it daily or even weekly may not consider quitting as a relevant option, as previously documented in the cigarette smoking literature ${ }^{48,49}$. In addition, not having used it in the past 4 months may not reflect volitional 
cessation, but could instead indicate that opportunities for hookah use may not have presented themselves or just an unintentional lapse in use.

Overall, current hookah user responses reflected consistency with previous research on reasons for hookah use $\mathrm{e}^{23,24,26,43}$, highlighting instrumentality (e.g. doesn't smell badly, comes in appealing flavors) as the most significant reason, followed by social reasons (e.g. people who are important to me use hookah, I like the image it reflects). The availability of various flavors along with experimenting with them was a primary reason for hookah use among current users. Never users mentioned the appeal of assorted flavors along with socializing with hookah users as their main reasons for potential use. Social reasons given in past research are that hookah smokers have a strong peer influence in initiation and imitation of the behavior ${ }^{16,31}$, and that students who smoke hookah have a greater number of friends who approve of hookah compared to never users ${ }^{17}$. Additionally, it is an affordable way to socialize ${ }^{16,18,21,22}$, appears cool and trendy ${ }^{12-14,50}$. These findings add to previous research examining hookah use among young adults, which documented that the constructs from the theory of reasoned action were all correlated with smoking behavior, and that use-related beliefs of users were more strongly associated with hookahrelated attitudes compared with subjective norms ${ }^{38}$.

It should be noted, however, that average ratings for each of the reasons for use among current use were below the mid-point (i.e. less than 3.5 on a 6-point scale), and that average ratings for the reasons for discontinued use were largely below the mid-point. These findings might indicate that there are other dominant reasons for use or discontinued use that were not assessed or that participants had little insight regarding their reasons for use or discontinued use. Moreover, never users rated each of the reasons for potential use quite low on average ( $\leq 1.37$ on a 6 -point scale), which may reflect similar phenomena or that never users are highly resistant to use on average.

Discontinued or former hookah users mentioned inconvenience of mess, cost, smell, flavor, or buzz, and anti-tobacco decisions to quit tobacco and nicotine all together, or found it unhealthy. Another emergent reason to discontinue smoking was social reasons - people didn't like the image it projected or were influenced by someone asking them not to use it. This finding is in agreement with past research, when family and friends' disapproval is a reason to stop smoking ${ }^{51,52}$. Indeed, the majority of waterpipe smokers are interested in quitting for social reasons ${ }^{51,52}$.

Findings from this study have implications for future research and practice. In terms of research, studies should focus on ways to effectively deliver messages to correct misperceptions about hookah, taking into account the acute/immediate and chronic/delayed consequences of using these products. There is a need to assess the impact of availability of various tobacco flavors within this population, as well as its role in hookah experimentation and progression to established use over time. Regarding practice, the findings of this study have implications for FDA regulations regarding hookah use. Since the majority of the participants liked the variety of tobacco flavors for hookah, flavor restrictions similar to those implemented for cigarettes under the Family Smoking Prevention and Tobacco Control Act may reduce the appeal of these products to them. University and college campus health-promotion initiatives should seek to promote positive health behaviors, and anti-hookah smoking efforts. Moreover, bolstering the social influences and other motives for cessation may be critical in curbing the hookah-use trend in young adults.

\section{Limitations}

Limitations to this study include limited generalizability of the findings due to localized recruitment, from colleges and universities in the Southeast region of the United States. Additionally, given the self-report nature of the assessments, findings are subject to bias. Finally, it is possible that we failed to tap some dimensions of the reasons for hookah use, potential use, and discontinued use; further research is needed to ensure exhaustive assessments of such dimensions.

\section{CONCLUSIONS}

The results from this study illustrate the widespread use of hookah among young adults. In particular, some young adults (those who are older, male, and Black) are at higher risk of hookah use. Moreover, young adults using other tobacco products, marijuana, or alcohol are more likely to use hookah. Among 
current users, there was low motivation to quit. We also documented reasons for using hookah among the current users and potential reasons for use among never users. Instrumentality and social reasons were the main factors for using hookah: mainly it does not smell badly, they enjoy experimenting with the variety of flavors, people close to them smoke hookah and the image it reflects. Particularly novel, we documented reasons for discontinued use among former hookah users. Discontinued or former users quit hookah use because they quit tobacco and nicotine all together, find it unhealthy or expensive, and due to the inconvenience of mess, smell, taste, or buzz. The variety of appealing flavors and socializing motivated the never users to potentially use hookah.

\section{REFERENCES}

1. U.S. Department of Health and Human Services. The Health Consequences of Smoking: 50 Years of Progress. A Report of the Surgeon General. 2014.

2. Fast Facts - Smoking \& Tobacco Use. (2017). Smoking and Tobacco Use. 2017. Available at: https://www.cdc. gov/tobacco/data_statistics/fact_sheets/fast_facts/ (accessed August 2017).

3. Warren CW, Lea V, Lee J, Jones NR, Asma S, McKenna M. Change in tobacco use among 13-15 year olds between 1999 and 2008: findings from the Global Youth Tobacco Survey. Glob Health Promot. 2009;16(2 Suppl):38-90. doi:10.1177/1757975909342192

4. Maziak W, Taleb ZB, Bahelah R, et al. The global epidemiology of waterpipe smoking. Tob Control. 2015;24 Suppl 1:i3-i12. doi:10.1136/tobaccocontrol-2014-051903

5. Jacob P, 3rd, Abu Raddaha AH, Dempsey D, et al. Nicotine, carbon monoxide, and carcinogen exposure after a single use of a water pipe. Cancer Epidemiol Biomarkers Prev. $2011 ; 20(11): 2345-2353$. doi:10.1158/1055-9965.epi-11-0545

6. Elsayed Y, Dalibalta S, Abu-Farha N. Chemical analysis and potential health risks of hookah charcoal. Science of The Total Environment. 2016;569-570:262-268. doi:10.1016/j.scitotenv.2016.06.108

7. Sepetdjian E, Saliba N, Shihadeh A. Carcinogenic PAH in waterpipe charcoal products. Food Chem Toxicol. 2010;48(11):3242-3245. doi: 10.1016/j.fct.2010.08.033

8. Blachman-Braun R, Del Mazo-Rodriguez RL, LopezSamano G, Buendia-Roldan I. Hookah, is it really harmless? Respir Med. 2014;108(5):661-667. doi:10.1016/j.rmed.2014.01.013

9. Bahelah R, DiFranza JR, Fouad FM, Ward KD, Eissenberg T, Maziak W. Early symptoms of nicotine dependence among adolescent waterpipe smokers. Tob Control. 2016 Dec;25(e2):e127-e134. doi:10.1136/tobaccocontrol-2015-052809

10. Wiseman KD, Cornacchione J, Wagoner KG, et al. Adolescents' and Young Adults' Knowledge and Beliefs About Constituents in Novel Tobacco Products. Nicotine Tob Res. 2016. 2016 Jul;18(7):1581-7. doi: $10.1093 / \mathrm{ntr} / \mathrm{ntw} 009$

11. Berg GJ, Stratton E, Schauer GL, et al. Perceived harm, addictiveness, and social acceptability of tobacco products and marijuana among young adults: marijuana, hookah, and electronic cigarettes win. Subst Use Misuse. 2015;50(1):79-89. doi:10.3109/10826084.2014.958857

12. Wong LP, Alias H, Aghamohammadi N, Aghazadeh S, Hoe VC. Shisha Smoking Practices, Use Reasons, Attitudes, Health Effects and Intentions to Quit among Shisha Smokers in Malaysia. Int J Environ Res Public Health. 2016;13(7).

13. Barnett TE, Lorenzo FE, Soule EK. Hookah Smoking Outcome Expectations Among Young Adults. Subst Use Misuse. 2017;52(1):63-70. doi:10.1080/10826084.2016.1214152

14. Wagoner KG, Cornacchione J, Wiseman KD, Teal R, Moracco KE, Sutfin EL. E-cigarettes, Hookah Pens and Vapes: Adolescent and Young Adult Perceptions of Electronic Nicotine Delivery Systems. Nicotine Tob Res. 2016 Oct;18(10):2006-12. doi:10.1093/ntr/ntw095

15. Primack BA, Sidani J, Agarwal AA, Shadel WG, Donny EC, Eissenberg TE. Prevalence of and associations with waterpipe tobacco smoking among U.S. university students. Ann Behav Med. 2008;36(1):81-86. doi:10.1007/s12160-008-9047-6

16. Roskin J, Aveyard P. Canadian and English students' beliefs about waterpipe smoking: a qualitative study. BMC Public Health. 2009;9:10. doi:10.1186/1471-2458-9-10

17. Noland M, Ickes MJ, Rayens MK, Butler K, Wiggins AT, Hahn EJ. Social influences on use of cigarettes, e-cigarettes, and hookah by college students. J Am Coll Health. 2016;64(4):319-328. doi:10.1080/07448481.2016.1138478

18. Baheiraei A. SS, Ebadi A., Kelishadi R., Majdzadeh R. Factors that Contribute in the First Hookah Smoking Trial by Women: A Qualitative Study from Iran. Iran J Public Health. 2015;44(1):100-110.

19. Kates FR, Salloum RG, Thrasher JF, Islam F, Fleischer NL, Maziak W. Geographic Proximity of Waterpipe Smoking Establishments to Colleges in the U.S. Am J Prev Med. 2016;50(1):e9-e14. doi:10.1016/j.amepre.2015.07.006

20. Sutfin EL, McCoy TP, Reboussin BA, Wagoner KG, Spangler J, Wolfson M. Prevalence and correlates of waterpipe tobacco smoking by college students in North Carolina. Drug Alcohol Depend. 2011;115(1-2):131-136. doi:10.1016/j.drugalcdep.2011.01.018

21. Nakkash RT, Khalil J, Afifi RA. The rise in narghile (shisha, hookah) waterpipe tobacco smoking: a qualitative study of perceptions of smokers and non smokers. $B M C$ 
Public Health. 2011;11:315.

doi:10.1186/1471-2458-11-315

22. Hammal F, Wild TC, Finegan BA. Knowledge About the Waterpipe (Hookah), a Qualitative Assessment Among Community Workers in a Major Urban Center in Canada. J Community Health. 2016 Aug;41(4):689-96. doi: 10.1007/s10900-015-0143-9

23. Villanti AC, Johnson AL, Ambrose BK, et al. Flavored Tobacco Product Use in Youth and Adults: Findings From the First Wave of the PATH Study (2013-2014). Am J Prev Med. 2017;53(2):139-151. doi:10.1016/j.amepre.2017.01.026

24. Castaneda G, Barnett TE, Soule EK, Young ME. Hookah smoking behavior initiation in the context of Millennials. Public Health. 2016 Aug;137:124-30.

doi:10.1016/j.puhe.2016.02.013

25. Khalil J, Heath RL, Nakkash RT, Afifi RA. The tobacco health nexus? Health messages in narghile advertisements. Tob Control. 2009;18(5):420-421. doi:10.1136/tc.2009.030148

26. Cornacchione J, Wagoner KG, Wiseman KD, et al. Adolescent and Young Adult Perceptions of Hookah and Little Cigars/Cigarillos: Implications for Risk Messages. J Health Commun. 2016;21(7):818-825. doi:10.1080/10810730.2016.1177141

27. Smith-Simone S, Maziak W, Ward KD, Eissenberg T. Waterpipe tobacco smoking: knowledge, attitudes, beliefs, and behavior in two U.S. samples. Nicotine Tob Res. 2008;10(2):393-398. doi:10.1080/14622200701825023

28. Brockman LN, Pumper MA, Christakis DA, Moreno MA. Hookah's new popularity among US college students: a pilot study of the characteristics of hookah smokers and their Facebook displays. BMJ Open. 2012;2(6). doi:10.1136/bmjopen-2012-001709

29. Akl EA, Ward KD, Bteddini D, et al. The allure of the waterpipe: a narrative review of factors affecting the epidemic rise in waterpipe smoking among young persons globally. Tob Control. 2015;24 Suppl 1:i13-i21. doi:10.1136/tobaccocontrol-2014-051906

30. Duke JC, Lee YO, Kim AE, et al. Exposure to electronic cigarette television advertisements among youth and young adults. Pediatrics. 2014;134(1):e29-36. doi:10.1542/peds.2014-0269d

31. Salloum RG, Osman A, Maziak W, Thrasher JF. How popular is waterpipe tobacco smoking? Findings from internet search queries. Tob Control. 2015;24(5):509513. doi:10.1136/tobaccocontrol-2014-051675

32. Sterling KL, Fryer CS, Majeed B, Duong MM. Promotion of waterpipe tobacco use, its variants and accessories in young adult newspapers: a content analysis of message portrayal. Health Educ Res. 2015;30(1):152-161. doi:10.1093/her/cyu035

33. Locke E, \& Bandura, A. Social Foundations of Thought and Action: A Social-Cognitive View. The Academy Of Management Review. 1987;12(1):169.
34. Berg CJ, Haardorfer R, Lewis M, et al. DECOY: Documenting Experiences with Cigarettes and Other Tobacco in Young Adults. Am J Health Behav. 2016;40(3):310-321. doi:10.5993/ajhb.40.3.3

35. Biener L, Abrams DB. The Contemplation Ladder - Validation of a Measure of Readiness to Consider Smoking Cessation. Health Psychol. 1991;10(5):360365. doi:10.1037//0278-6133.10.5.360

36. Maziak W, Ward KD, Afifi Soweid RA, Eissenberg T. Tobacco smoking using a waterpipe: a re-emerging strain in a global epidemic. Tob Control. 2004;13(4):327-333. doi:10.1136/tc.2004.008169

37. Jawad M, McEwen A, McNeill A, Shahab L. To what extent should waterpipe tobacco smoking become a public health priority? Addiction. 2013;108(11):18731884. doi:10.1111/add.12265

38. Martinasek MP, Haddad LG, Wheldon CW, Barnett TE. Beliefs and Attitudes Associated with Waterpipe Smoking Among a US College Population. Respiratory Care. 2017;62(3):370-379. doi:10.4187/respcare.05069

39. Amos A, Greaves L, Nichter M, Bloch M. Women and tobacco: a call for including gender in tobacco control research, policy and practice. Tob Control. 2012;21(2):236243. doi: 10.1136/tobaccocontrol-2011-050280

40. Grinberg A, Goodwin RD. Prevalence and correlates of hookah use: a nationally representative sample of US adults ages 18-40 years old. Am J Drug Alcohol Abuse. 2016;42(5):567-576.

doi:10.3109/00952990.2016.1167214

41. Jamil H, Elsouhag D, Hiller S, Arnetz JE, Arnetz BB. Sociodemographic risk indicators of hookah smoking among White Americans: a pilot study. Nicotine Tob Res. 2010;12(5):525-529. doi:10.1093/ntr/ntq026

42. Villanti AC, Cobb CO, Cohn AM, Williams VF, Rath JM. Correlates of hookah use and predictors of hookah trial in U.S. young adults. Am J Prev Med. 2015;48(6):742-746. doi:10.1016/j.amepre.2015.01.010

43. Baheiraei A, Shahbazi Sighaldeh S, Ebadi A, Kelishadi R, Majdzadeh R. The Role of Family on Hookah Smoking Initiation in Women: A Qualitative Study. Glob J Health Sci. 2015;7(5):1-10. doi:10.5539/gjhs.v7n5p1

44. Organization WH. WHO calls for protection of women and girls from tobacco. 2013; Available at: http://www. who.int/mediacentre/news/releases/2010/women_ tobacco_20100528/en/ (accessed August 2017)

45. Calvanese AV, Bingham MV, Martinasek MP, Friesen BK. Understanding Attitudes, Beliefs, and Information Seeking Regarding Hookah Smoking in Parents of College Students: An Exploratory Qualitative Pilot Study. Respir Care. 2015;60(7):959-966. doi:10.4187/respcare.03726

46. Gilreath TD, Leventhal A, Barrington-Trimis JL, et al. Patterns of Alternative Tobacco Product Use: Emergence of Hookah and E-cigarettes as Preferred Products Amongst Youth. J Adolesc Health. 2016;58(2):181-185. 
47. Martinasek MP, McDermott RJ, Martini L. Waterpipe (hookah) tobacco smoking among youth. Current Problems in Pediatric and Adolescent Health Care. 2011;41(2):3457. doi:10.1016/j.cppeds.2010.10.001

48. Berg CJ, Lust KA, Sanem JR, et al. Smoker selfidentification versus recent smoking among college students. Am J Prev Med. 2009;36(4):333-336.

doi:10.1016/j.amepre.2008.11.010

49. Berg CJ, Schauer GL, Buchanan TS, et al. Perceptions of addiction, attempts to quit, and successful quitting in nondaily and daily smokers. Psychol Addict Behas. 2013;27(4):1059-1067. doi:10.1037/a0033790

50. Hammal F, Wild TC, Nykiforuk C, Abdullahi K, Mussie D, Finegan BA. Waterpipe (Hookah) Smoking Among Youth and Women in Canada is New, not Traditional. Nicotine Tob Res. 2016;18(5):757-762. 10.1093/ntr/ntv152

51. Ward KD, Hammal F, VanderWeg MW, et al. Are waterpipe users interested in quitting? Nicotine Tob Res. 2005;7(1):149156. doi:10.1080/14622200412331328402

52. Borgan SM, Marhoon ZA, Whitford DL. Beliefs and perceptions toward quitting waterpipe smoking among cafe waterpipe tobacco smokers in Bahrain. Nicotine Tob Res. 2013;15(11):1816-1821. doi:10.1093/ntr/ntt064

ACKNOWLEDGEMENTS

We would like to thank our Campus Advisory Board members across the State of Georgia in developing and assisting in administering this survey. We also would like to thank ICF Macro for their scientific input and technical support in conducting this research.

CONFICTS OF INTEREST

All authors have completed and submitted the ICMJE Form for Disclosure of Potential Conflicts of Interest and none was reported.

\section{FUNDING}

This research was supported by the National Cancer Institute (1R01CA179422-01; PI: Berg). The funders had no role in the study design, collection, analysis, or interpretation of the data, writing of the manuscript, or the decision to submit the paper for publication.

PROVENANCE AND PEER REVIEW

Not commissioned;

externally peer reviewed 